\title{
Erratum to: Honokiol activates
} AMP-activated protein kinase in breast cancer cells via LKB1-dependent pathway and inhibits breast carcinogenesis

\author{
Arumugam Nagalingam', Jack L. Arbiser ${ }^{2}$, Michael Y. Bonner ${ }^{2}$, Neeraj K. Saxena ${ }^{3}$ and Dipali Sharma ${ }^{1 *}$
}

\section{Erratum}

After the publication of this work [1], an error was noticed in Fig. 1b. An incorrect image was inadvertently shown for the soft-agar colony for MDA-MB-231 cells treated with $5.0 \mathrm{uM}$ Honokiol. The correct figure is shown below. This error did not affect the findings or conclusions of the article.

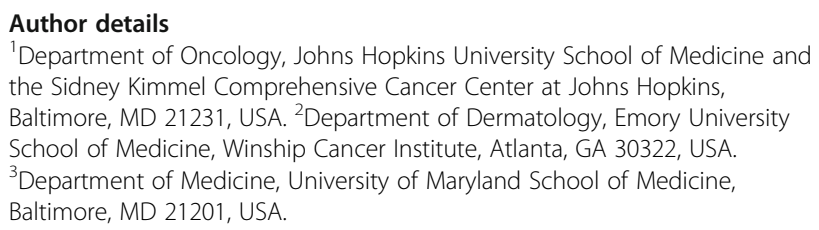

Received: 6 March 2017 Accepted: 6 March 2017

Published online: 28 March 2017

\section{Reference}

1. Nagalingam A, et al. Honokiol activates AMP-activated protein kinase in breast cancer cells via an LKB1-dependent pathway and inhibits breast carcinogenesis. Breast Cancer Res. 2012;14(1):R35.

\footnotetext{
* Correspondence: dsharma7@jhmi.edu

'Department of Oncology, Johns Hopkins University School of Medicine and the Sidney Kimmel Comprehensive Cancer Center at Johns Hopkins, Baltimore, MD 21231, USA

Full list of author information is available at the end of the article
} 


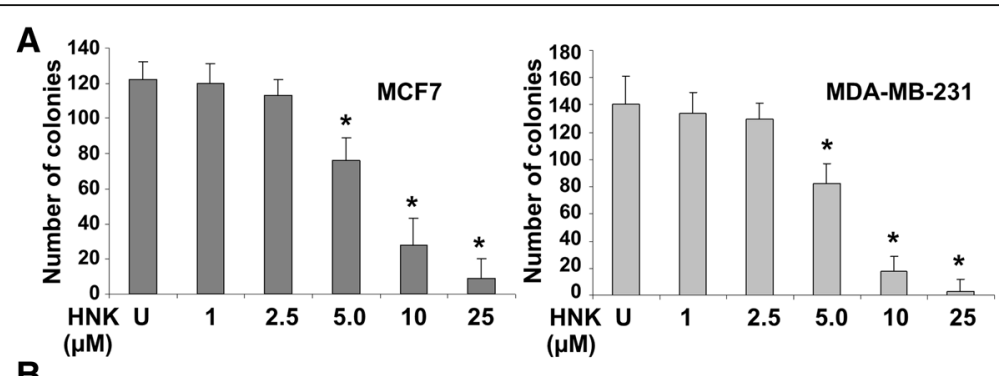

B
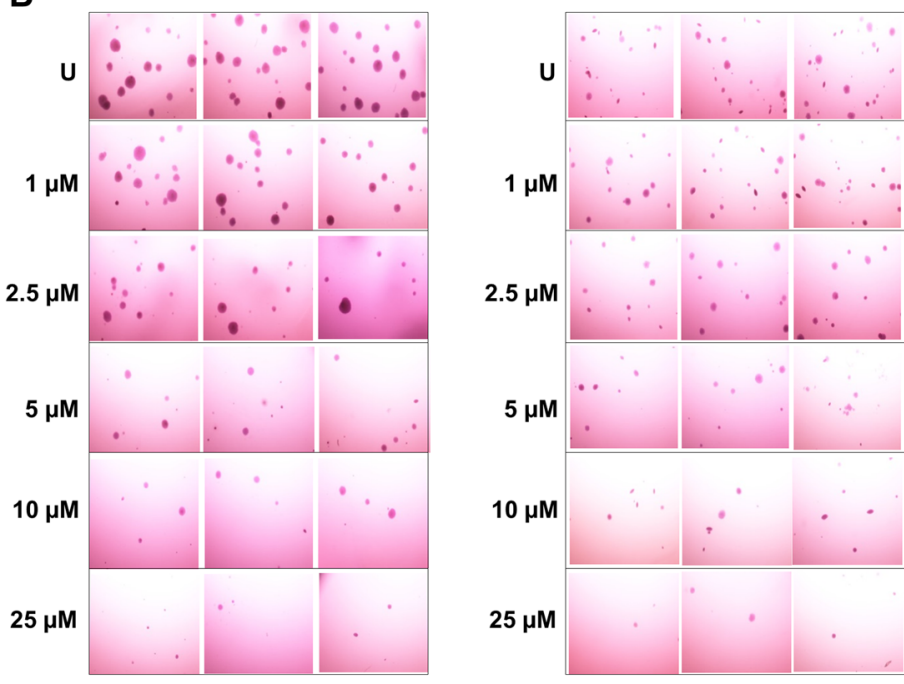

MCF7

MDA-MB-231
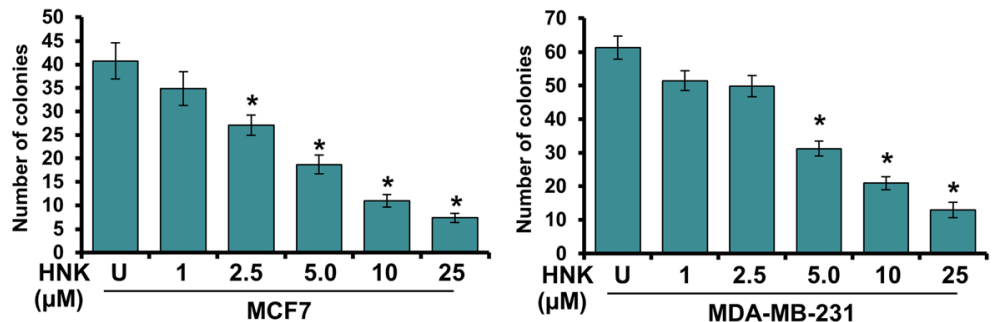

Fig. 1 Honokiol inhibits clonogenicity and anchorage-independent growth of breast cancer cells. a MCF7 and MDA-MB-231 cells were treated with various concentrations of honokiol (HNK) (as indicated) and subjected to clonogenicity assay. Untreated cells, denoted with the letter " $U$ ". Colonies containing $>50$ normal-appearing cells were counted. ${ }^{*}, P<0.005$, compared with untreated controls. $\mathbf{b}$ Breast cancer cells were subjected to soft-agar colony-formation assay in the presence of various concentrations of honokiol for three weeks. Untreated cells are denoted with the letter " $U$ ". Results are expressed as average number of colonies counted (in six micro-fields). ${ }^{*}, P<0.001$, compared with untreated controls 